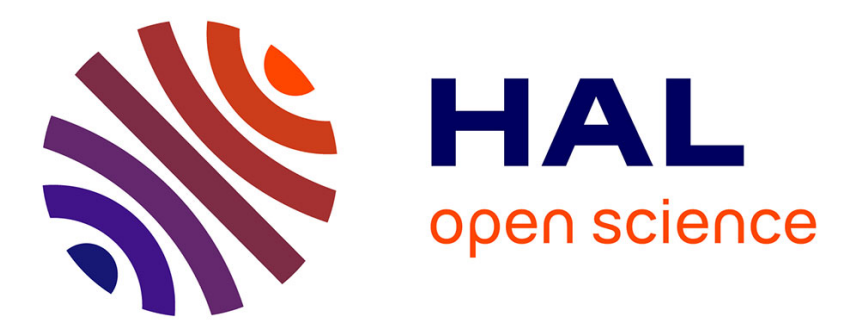

\title{
Experiences of Teaching HCI to a Multidisciplinary Cohort of Computing and Design Students
}

\author{
Omar Mubin, Abdullah Al Mahmud, Suleman Shahid
}

\section{To cite this version:}

Omar Mubin, Abdullah Al Mahmud, Suleman Shahid. Experiences of Teaching HCI to a Multidisciplinary Cohort of Computing and Design Students. 15th Human-Computer Interaction (INTERACT), Sep 2015, Bamberg, Germany. pp.542-545, 10.1007/978-3-319-22723-8_57 . hal-01610774

\section{HAL Id: hal-01610774 \\ https://hal.inria.fr/hal-01610774}

Submitted on 5 Oct 2017

HAL is a multi-disciplinary open access archive for the deposit and dissemination of scientific research documents, whether they are published or not. The documents may come from teaching and research institutions in France or abroad, or from public or private research centers.
L'archive ouverte pluridisciplinaire HAL, est destinée au dépôt et à la diffusion de documents scientifiques de niveau recherche, publiés ou non, émanant des établissements d'enseignement et de recherche français ou étrangers, des laboratoires publics ou privés. 


\title{
Experiences of Teaching HCI to a Multidisciplinary Cohort of Computing and Design Students
}

\author{
Omar Mubin ${ }^{1}$, Abdullah Al Mahmud ${ }^{2}$, and Suleman Shahid ${ }^{3}$ \\ ${ }^{1}$ University of Western Sydney; Australia, ${ }^{2}$ Swinburne University of Technology, \\ ${ }^{3}$ Tilburg center for Cognition and Communication, Tilburg University; Netherlands
}

\begin{abstract}
In this paper we present our initial insights on the redesign of an undergraduate unit on Human Computer Interaction to suit a mixed cohort of Computing and Design students. In order to address the diversity in student background we implemented an open brief project assessment. We summarise changes to the unit and present sample student projects that emerged from the unit as outcomes.
\end{abstract}

Keywords: HCI Education, Design

\section{Introduction}

Pedagogical methodologies in the area of HCI follow numerous strategies, encouraged perhaps by the freedom provided by HCI as a discipline. These include a hands on studio approach [6] or a case study based assessment [5]. Researchers acknowledge that HCI education must be tailored to the background of the students. For example prior work has considered how the content, assessments and learning outcomes may be adapted to computing students [1]. Similar endeavors have been reported for engineering students [3] and for design students [2], where for the former the focus was on problem solved based learning and for the latter the emphasis was on the design and evaluation of tangible artifacts. HCI is a common and usual occurrence in most Computing undergraduate programs however it is slowly gaining ascendancy in Design, Arts and Interaction Design Programs, mainly due to the rise of innovative products such as those from Apple where aesthetics is an important design consideration. Upon analyzing prior work it is observed that there are not extensive insights on measures to employ if the student cohort is mixed in discipline. This is precisely the challenge that was confronted in coordinating the Human Computer Interaction unit at the University of - where both Computing and Design students were being offered the unit (with no pre-requisites) due to course restructures on both sides. The previous version of the unit was only offered to computing students and was heavily focused on Graphical User Interface Design with a theoretical exam having $50 \%$ contribution towards the final grade. It was evident that to facilitate the integration of both Design and Computing students of varying year levels 
(1-3), unit changes were required both in depth and in breadth, i.e. in content as well as in assessment offerings. Our approach in the reformed unit was along the lines of designed thinking with a hands on approach; developing empathy with a user group, finding inadequacies and thereby solutions for those problems.

\section{Changed Unit Proposal for HCI}

The following guidelines were proposed and approved by the university's administration via a changed unit proposal:

- Assessments must advocate a hands-on approach (i.e. practical and utilizing creative skills). This is has also been argued for in prior work in HCI education [7], where a constructivist ideology was proposed to support learning across disciplines.

- Assessments must have at least a half in half element of both Design and Computing aspects. For example have as much of a Design/Conceptualization phase as a Development/Implementation/Programming phase.

- Encourage group-based assessments allowing students to collaborate with each other and potentially endorse Design and Computing students to work together.

- Employ a relatively open brief, in order to allow students to explore their interests and a wide design space.

- Develop a marking criterion that takes into account the background of the student. One of the elements that were hence incorporated was that the base requirement of the assessments was standardized across the unit (i.e. all students had to design at least three scenarios and implement at least one of them). Consequently, students were then allowed to build upon the base requirements according to their own preferences.

- Build upon the assessments in the tutorials, allowing students to exchange ideas with their peers and their tutors.

- Lecture content was adapted so project ideas were facilitated and mediated. For example special guest lectures were arranged which showcased novel project ideas and upcoming state of the art techniques in HCI.

The freedom that was extended to the students in the project brief also extended to the choice of the tools that they could employ to create solutions. For each project assessment a minimum of three tools were discussed in lectures and tutorials therefore allowing a wide array of possibilities to the students. In addition to allow better integration of both disciplines of Design and Computing facilitation techniques were employed. For example, Interface Design was propagated to Computing Students via software based methodologies (such as wireframing software, for e.g. Balsamiq, Just in Mind Prototyper) and not paper, thereby allowing them to overcome any deficiencies in hand sketching. On the other hand strategies employed to instruct programming to students from non-technical background included script based and graphical programming languages (such as Arduino using Max/MSP), with the ultimate goal of reducing 
the learning curve. Content taught in lectures was supplemented in the tutorial sessions where students could practice using the tools under the supervision of the tutors. It is worth mentioning this unit was the only HCI unit being offered with no graduate options, therefore course content was generally delivered in breadth providing a flavour of all stages of a typical design process in HCI. The primary assessments for the unit were weekly tutorial exercises and one project that would run across the semester. The project was performed by a group of 2-4 students. Each project was evaluated at 3 checkpoints. These included: 1) a project brief proposal written in the form of a report; 2) low-fidelity prototype details (typically wireframe designs or product sketches) submitted in the form of a written report and 3) hi-fidelity semi-functional prototype showcased as a demo presentation in the last week of the semester in addition to an evaluation plan of their prototype.

\section{Student Projects}

We now discuss the impact of the changes in relation to some example projects. Total enrolment in the unit was more than 300 , so we present 4 of the most exemplary projects in this paper.

1. Case Study 1: Design Students

A group of 3 Design students worked on the re-design of a TV remote control for the elderly. The students performed well in the conceptualization phase of the project, where an efficient low fidelity prototype was built using a 3D printer. They incorporated electronics in their prototype for the second phase of their project (see Figure 1). However they could only implement one feature in their working concept.

2. Case Study 2: Computing Students

A group of 2 computing students created an online shopping website for home furniture. The solution allowed for real time three-dimensional visualization of a certain piece of furniture. Despite the novelty of this feature, the team was let down by aesthetics and layout chosen for their website.

3. Case Study 3: Design and Computing Students in collaboration; focusing on the design of a mobile app

A group comprised of 4 students (3 Computing and 1 Design) created a mobile application for the elderly that allowed the user to translate textual phone messages if they were written in slang (for e.g. acronyms such as lol, brb, etc.). The Design student took care of the layout, drawings and sketches of the application and the computing students implemented the functionality of it. The final solution was an almost market ready application for Android mobile phones.

4. Case Study 4: Design and Computing Students in collaboration; focusing on the design of a tangible artifact

A group of 3 students (2 Design and 1 Computing) took on a unique challenge of redesigning a gun as a gaming controller and providing tactile and real time feedback (see Figure 1). The Design students took care of the 
physical casing and electronics of the prototype and the Computing student implemented the sensor technology inside the controller.
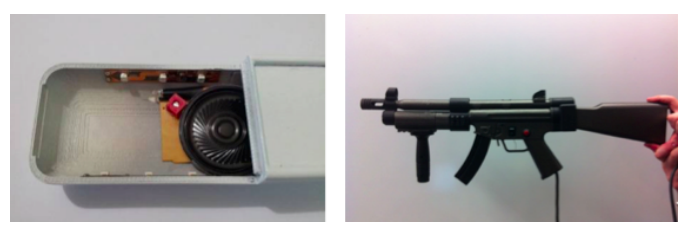

Fig. 1. Examples of Prototypes created by Students

\section{Conclusion}

By reviewing student output in the unit of HCI, a trend seems to appear. Projects that involved both design and computing students collaborating together delivered the most complete, well-executed and well-motivated outcome. Expertise of each student was utilized in full and brought on board, with a complete chance to each student to express him/herself in areas that they were the most comfortable in. Similar findings w.r.t the benefits of collaborative learning in HCI have been reported [4]. In addition the uniqueness of our approach is the open brief adopted for the unit, which resulted in a wide array of projects with students taking the freedom to facilitate their creativity. Nevertheless, future work in continued restructuring of the unit must contemplate how to encourage enhanced cross disciplinary work regardless of, if the students are in cross disciplinary groups or not.

\section{References}

1. Chan, S., Wolfe, R., Fang, X.: Teaching hci in is/ec curriculum. In: Americas Conference on Information Systems. pp. 1011-1020 (2002)

2. Ciolfi, L., Cooke, M.: Hci for interaction designers: Communicating" the bigger picture. Inventivity: Teaching Theory, Design and Innovation in HCI 1, 47-51 (2006)

3. Larsen, L.B., Andersen, S.K., Fink, F.K., Granum, E.: Teaching hci to engineering students using problem based learning (2009)

4. Lester, C.Y.: Advancing the multidisciplinary nature of human computer interaction in a newly developed undergraduate course. In: Conference on Advances in Computer-Human Interaction. pp. 177-182. IEEE (2008)

5. McCrickard, D.S., Chewar, C.M., Somervell, J.: Design, science, and engineering topics?: teaching hci with a unified method. SIGCSE Bulletin 36(1), 31-35 (2004)

6. Reimer, Y.J., Douglas, S.A.: Teaching hci design with the studio approach. Computer science education 13(3), 191-205 (2003)

7. Vat, K.H.: Teaching hci with scenario-based design: the constructivist's synthesis. In: ACM SIGCSE Bulletin. vol. 33, pp. 9-12. ACM (2001) 